\title{
The Impact of the Public Procurement Control System on the Hungarian Public Administration
}

\author{
Györgyi Nyikos \\ National University of Public Service, Budapest, Hungary \\ nyikos.gyorgyi@uni-nke.hu \\ Gábor Soós \\ National University of Public Service, Budapest, Hungary \\ soos.gabor.gergely@uni-nke.hu
}

\section{ABSTRACT}

The complexity of public procurement and the related controls are a significant issue that public authorities are facing in Hungary. The "fear" of being controlled by state authorities and EU auditors is affecting decisions in public procurement. However, research on the effects of such a system is largely absent. The purpose of the article is to explore the functioning of the control system related to EU funded public procurements and to examine its actual and potential impact on the purchases of public authorities. The method is first an introduction of the features of the control system and then the analysis of data from the relevant bodies in order to see the effect of controls and possible difficulties with the system. The results show that despite the seemingly positive impact on the regularity of procedures, the interference in the decisions of public authorities and the delays caused are problematic. It is therefore suggested that the Hungarian government should consider streamlining the control process such as through checks based on samples or focusing on the most risky procedures. The research is the first academic analysis of data related to public procurement control in Hungary, yet it can already inspire the Hungarian and other governments to review the effectiveness of such procedures and to reduce administrative burdens for public authorities as much as possible.

Keywords: public procurement, administrative burden, audit, ex ante controls, EU funds, Hungary

JEL: H11, H7O, K39 


\section{Introduction}

When purchasing goods and services public administration bodies across the European Union must use a public procurement procedure. This can be a long and complicated process which can often be challenging for public authorities. The process of purchasing through public procurement involves a number of stages and in each of these the public authority (contracting authority) has to make some kind of decision. In case the procedure is not followed, remedies may be sought before the national review bodies where damages can be awarded or even the contract may be declared ineffective. In addition, the correct use of public procurement receives special attention in the context of EU funded projects, since an incorrect application of the rules ${ }^{1}$ can lead to a finding of irregularities and therefore financial corrections (i.e. a withdrawal of funding from a project) (European Commission, 2013).

The use of EU funds is monitored by a number of bodies including the European Commission, the European Court of Auditors and national audit authorities. In order to avoid public procurement irregularities, it is useful to establish additional control systems at national level which help to avoid these. Here we focus on controlling the legality of the actions of contracting authorities. This can also be referred to as supervision of public procurements (Bianchi and Guidi 2010) or audit of compliance (OECD, 2013).

Hungary has established a control system for EU funded public procurements. While all EU Member States are obliged to have adequate systems of supervision and control, no other country is known in Europe that would control public procurements on such a large scale. The Hungarian system involves controlling documents and procedures both ex ante and during the procedure itself for all EU funded procurements above the EU thresholds for goods and services and above HUF 300 million (approx. EUR 1 million) for works contracts. ${ }^{2}$ In addition, ex post controls exist for all procedures below these values.

The principal aim of this article is to show the functioning of the Hungarian control system and to investigate how this rigorous control system is impacting on the functioning of public authorities, when the procurement is at least partially funded from EU sources. The article includes both a theoretical analysis of the difficulties related to the control system and data received from the control body is also analysed in order to estimate the actual effect of controls on the behaviour of public authorities. Our hypothesis is that public authorities take more care when carrying out public procurement, although this, and the length of the control process itself is likely to cause delays in the process. Further, if the procurement is not prepared with due care, then this can result in even more interruptions in the process due to repeated calls for

1 Public procurement in the EU is governed by the public procurement directives, i.e. Directive 2014/23/EU, Directive 2014/24/EU and Directive 2014/25/EU.

2 The general EU threshold for goods and services is EUR 144000 for central government authorities, EUR 221000 for other contracting authorities and EUR 5548000 for works contracts. A separate control system exists for certain public procurements funded from purely national funds, but this article focuses on EU funded public procurements. 
missing documents by the control body or a refusal to grant a green light for the process. While little reference can be found in the academic literature to such an analysis of control systems of other countries, brief mention is also made of the types of controls that exist elsewhere.

The present article first describes the processes involved in EU public procurement procedures and the mandatory controls carried out by the Hungarian control authorities and how this compares with the systems in other countries. A theoretical analysis on the possible impact on the control system is followed by a discussion and analysis of data received from the Department of Public Procurement Control (DPPC) of the Prime Minister's Office to see also how far the figures confirm that the control system has a real effect on the public procurement procedures. Finally it is discussed whether the level of interference in public procurement procedures is too high or whether the rate of irregularities really makes the application of this system necessary.

\section{Key Stages of the Public Procurement Procedure}

Conducting a public procurement procedure involves a significant amount of preparation and a number of decisions. Preparation and planning are critical and influence all future activity on the contract. However it is often the case that the contracting authority will either underestimate the planning stage of the process or not carry it out at all (European Union, 2015). The most significant decision that has to be made during the preparation process is the 'decision on what to purchase'. Неге we are concerned with the choice of a contracting authority as to what goods, services or works it wishes to purchase in order to fulfil its needs. While the Directives do not impose restrictions on "what to buy", in fact for EU funded projects there are restrictions imposed by EU legislation in form of the so called eligible costs. So for the eligibility part the contracting authority who is a beneficiary of EU funds must carefully select the goods, service or works it wishes to buy from the funds awarded to it.

\subsection{Preparatory stages}

Once the first step described above is made, it must be decided how the purchase is going to be made, i.e. whether a public procurement is necessary. Any purchase has to be made by means of a formal public procurement procedure, as long as the estimated value of the procurement exceeds the thresholds set out in the Directives (or the corresponding national legislation). Nevertheless, the contracting authority should check whether any exceptions ${ }^{3}$ in the Directive are applicable.

\subsection{Designing the procedure}

As long as it has been established that a public procurement procedure is necessary, the procedure has to be planned very carefully. All necessary informa-

3 E.g. in-house procurement, research and development services etc. 
tion has to be set out in the procurement documents, which has to be made available to all the potential tenderers interested in the contract.

An important feature of the procurement documents is the definition of technical specifications which is a detailed description of the product, service or work to be purchased. The decision as to what to put in the technical specifications can be influenced by the involvement of experts, and also by the rules that ensure that there is no discrimination against certain economic operators. Where possible, specifications should be defined in terms of performance or functional requirements and if there is a reference to certain standards or if standards or in exceptional cases specific makes or sources are referred to, the description must use the words 'or equivalent'.

The contracting authority must also make an important decision when choosing the most appropriate procedure for conducting the procurement. Under the Directive, open and restricted procedures can always be used, while other types (competitive procedure with negotiation, competitive dialogue and negotiated procedure without publication of notice) are only available if certain strict conditions are met.

Another important aspect of the procedure is the definition by the public authority as to what selection criteria and award criteria should apply during the procedure. The contracting authority may also set conditions for the performance of the contract, which, according to the Directive, may include economic, innovation-related, environmental, social or employment-related considerations.

\subsection{Conducting the procedure and awarding contract}

Once the procurement documents have been prepared and tenders (or requests to participate) have been submitted, a series of decisions have to be made during the conduct of the procedure. First the contracting authority must establish whether the tenders (or requests to participate) conform to the conditions set out in the procurement documents and the applicable legislation. In case some documents have not been submitted, a request for the supply of missing information should be issued to the tenderers concerned. Under this principle only minor errors may be corrected and any changes must not affect any features of the offer which are evaluated under the award criteria. So, whether to allow the supply of missing information or correct errors is an important decision, again, subject to legislative restrictions and strict controls.

Probably the most important decision that a contracting authority has to make in a public procurement procedure is to whom the contract should be awarded. This must be based on the evaluation of tenders on the basis of the award criteria set out in the procurement documents. In case only numerical criteria are used (e.g. price and cost only) then the selection of the winner is essentially automatic, based on the tenders submitted. However, in case subjective criteria are used (e.g. aesthetic characteristics, quality of staff), then the contracting authority does have a certain amount of discretion in 
the evaluation of these aspects. Nevertheless, this discretion is again limited by the principles of equal treatment and transparency, which is subject to the control mechanisms described in section 3.

Finally one must mention that a decision whether, after the its signature, the contract should be modified, is also strictly limited by the Public Procurement Directives. Modifications without assessment of the strictly defined conditions are inter alia possible where the so called de minimis conditions are fulfilled: where the value of the modification is below 1 ) the EU threshold values, and 2) $10 \%$ of the initial contract value for service and supply contracts and below $15 \%$ of the initial contract value for works contracts. In addition the modification may not alter the overall nature of the contract.

\section{The Public Procurement Control System}

\subsection{The necessity and possible effects of establishing a control system}

In general, efficient enforcement is of utmost importance for compliance with the rules in any field of law, including public procurement (Arrowsmith 2011). The EU obliges all Member States to have an effective remedies system in order to increase compliance with the rules. However this is not always thought to be sufficient, since applying for remedies might be a costly and burdensome exercise and not all interested parties might be willing to start a case before the competent review bodies. So most EU Member States have decided to set up additional control systems to increase compliance with the legislation on public procurement.

The control processes receive special attention in the context of EU funds, due to the severe sanctions and the possible loss of funding. The statistics also show that public procurement is a risky area in the context of using EU funds. In fact when spending EU funds, public procurement is the area most affected by irregularities in the EU Member States. For the 2007-2013 EU programming period, 349 billion euro was allocated in the area of cohesion policy through the European Regional Development Fund (ERDF), the Cohesion Fund (CF) and the European Social Fund (ESF). Almost half of all projects in relation to these three funds audited by the European Court of Auditors (ECA) over the 2009-2013 period involved one or several tenders (ECA, 2015). According to the experience of audits, the infringement of the public procurement rules was the most significant type of irregularity that occurred during the implementation of the Funds mentioned (ECA, 2015). According to a system audit of ECA in 2011, 44\% of quantifiable errors were related to public procurement (ECA, 2011). These infringements can have serious consequences. If a breach of the rules is found, then the European Commission (or the Member State authorities) may impose financial corrections, meaning that the EU financial support from the project is partially or totally withdrawn. In addition if the public procurement system does not function properly, pay- 
ment of funds may also be suspended, causing potential delays in the necessary payments to be made.

Public procurement procedures also involve a quite high corruption risk. This partly comes from the fact that large sums are available from EU funds and there is some discretion on how to allocate funding. A study involving the Czech Republic, Slovakia and Hungary revealed that when additional public resources became available for discretionary allocation, there was a considerable increase of corruption but this could be counter-balanced by more stringent regulation, monitoring, and transparency (Fazekas et. al. 2013). The risk of corruption involving EU funds is also an issue in other countries such as Romania, which also has a large share of EU funds in its public spending (Dimulescu et al. 2013). Beyond the European context, in the American literature we can also find reference to the importance of internal controls to fight procurement fraud (Rendon and Rendon 2015).

When concluding its Partnership Agreement for the use EU funds, the European Commission established that Hungary did not meet the so called ex ante conditionality related to public procurement. The evaluation related for example to the arrangements for the effective application of EU public procurement rules and ensuring the adequate transparency of award procedures. Therefore an action plan was agreed with the Commission in order to ensure compliance. A proper control system was a key feature of the action plan, ensuring the fulfilment of the conditions established. Therefore a desire to reduce the number of irregularities coupled with a pressure from the Commission was the main reason to establish the current system of controls.

In light of the above, strict controls of EU funded public procurement have the aim of ensuring the lawful spending of funds and avoiding the loss of funding from the EU through changing the attitudes and behaviour of public authorities. If funds are withdrawn, then the burden of paying for the projects in question falls exclusively on the national budgets. While changing the behaviour of authorities is a key element to success, it is also important to design the control process in a way that does not constitute an excessive burden for public authorities that receive EU funds. In particular the delays, the administrative burdens and the autonomy of the decision-making should be minimised. Nevertheless our hypothesis is that a "fear" of being controlled always changes the way in which the controlled entities behave. In an ideal situation they ensure that their procurement decisions are always in conformity with the public procurement rules and therefore auditors will not find any irregularities in the procurement processes. Furthermore, strict control can also cause them to be very careful in the application of the rules, leading to a situation where they do not carry out their procurement in the most official and optimal way, but use procedures and criteria which surely conform to the relevant legislation.

For monitoring the correct use of EU funds, Hungary has opted for a very strict control system, which has various elements of ex ante, ex post control and control integrated in the process. This is supplemented by the manda- 
tory remedies system required by EU law ${ }^{4}$ other checks by national audit authorities and the control of public procurement notices by the Public Procurement Authority. The key feature of the system is that practically all EU funded public procurement procedures are subject to the mandatory control process. The main Hungarian body responsible for the control of public procurements funded from EU funds is the Department for Public Procurement Control (DPPC) of the Prime Minister's Office. Lower value procurements are controlled by the competent Managing Authority (authority responsible for selecting beneficiaries of EU funds). The control system is described below in more detail.

\subsection{The international perspective}

The amount of literature on the control systems of other countries is fairly scarce. Nevertheless from the information available it can be seen that they tend to be less comprehensive than the Hungarian system. A detailed comparative study has been carried out for the Public Procurement Network by Bianchi and Guidi (2010), which can offer an insight into the institutional system of EU Member States, including the authorities responsible for the supervision of public procurements. According to the study, a number of countries, such as Italy, Austria, Belgium, Bulgaria, Greece and Spain appoint their national court of auditors to control the legality of public procurement procedures. In other countries the role of supervision and control is carried out by specialised bodies that belong to the government structure (Lithuania, Poland, Romania, Slovakia and Malta). In Slovenia, audits are carried out by the National review Commission whose members are nominated by Parliament. In some countries the supervision of public procurements belong to the national competition authority, which is the case in the Czech Republic, Sweden, Finland, the Netherlands and Denmark. In Greece, controls are carried out before the conclusion of the contract by the national court of auditors for contracts above EUR 1 million. In Italy an independent body, the Authority for the Supervision of Public Contracts has been set up.

In Poland the main controller of procurement procedures compliance is the Public Procurement Orders Agency, which carries out scheduled and unscheduled documentary inspections of procurement at the request of state bodies, public organizations and citizens and analyses information in the procurement bulletin. Procurements that are financed or co-financed by EU funds, equal to or exceeding EUR 10 million in respect of the procurement of goods and services and EUR 20 million in the case of works are subject to mandatory control (Yaremenko and Shatkoviskiy). Further, a good example of a country taking steps to fight corruption in public procurement is Malta, which has also established a system investigating fraud and corruption in Public Procurement, where after receiving any form of reporting concerning fraudulent activities in public procurement, the Director of Contracts, after

4 Directive 89/665/EEC on the coordination of the laws, regulations and administrative provisions relating to the application of review procedures to the award of public supply and public works contracts (as emended by Directive 2007/66/EC) 
having conducted his own investigations, can forward reports and findings to the Police Commissioner or the Internal Audit and Investigations Department (Department of Contracts 2017).

The main feature of the supervisory bodies mentioned is that unlike in the Hungarian case, their controls are based on a sample of procedures and in some cases on complaints, so generally they do not control every single procedure. In Sweden for example priority is given to cases where the authority thinks that their actions will have the desired effect (SCA, 2016). The Finnish authority also seeks to focus on the essential issues and avoid inflexible and prolonged procedures (FCCA, 2017). Furthermore, generally the approach of other countries outside Hungary is that no prior consent of the control body is required to launch the procedure or to award and conclude the contract. For example in the case of Poland, in general the Public Procurement Orders Agency may make recommendations, turn to the review body or fine the contracting authority (Yaremenko and Shatkoviskiy). As we saw above, mandatory ex ante controls do also exist in Poland, however their thresholds are much higher than in the case of Hungary. Finally it should be reiterated that controls of national courts of auditors generally close with a report stating the evaluation of the controlled activities and containing recommendations on how to address these (Mazur 2016).

\subsection{Ex ante controls}

In Hungary, ex ante controls are carried out by the DPPC for public supply contracts, public service contracts and public service concessions reaching or exceeding the EU thresholds and for public works contracts and public works concessions reaching or exceeding HUF 300 million (approx. EUR 1 million). In this control process both the competent Managing Authority and the DPPC are involved.

As a first step the contracting authority (who in this case is also the beneficiary) must send the procurement documents to the Managing Authority who checks the eligibility, accountability and technical aspects of the procurement within 5 working days. The contracting authority must modify the documents, if necessary, in accordance with the comments of the Managing Authority. Then the contracting authority sends the procurement documents to the DPPC for ex ante control. Control by the DPPC is carried out in two stages. First the DPPC checks whether exclusion criteria, selection criteria, award criteria, contract performance conditions and securities ensuring contract performance have been defined in conformity with the public procurement rules. A certificate on the launching of the procedure is issued within 5 working days. If it is found that some aspect of the procedure does not comply with the law, then the documents, including the contract notice must be amended. When this process is complete, the DPPC checks all other public procurement law aspects of the relevant documents within another 5 working days. During both processes calls for missing documents may also be issued, which can slow down the process considerably. Finally a supportive certificate, a supportive certificate with 
conditions or a non-supportive certificate is issued with respect to the contract documents. In the second case amendments to the documents must be made, while in the last case the documents must be withdrawn.

It must be highlighted that until the end of 2016, the ex ante control was carried out in one step and the contracting authority was barred from starting the procedure until a supportive certificate (with or without conditions) was issued by the DDPC. However the legislation in force from 1 January 2017 now allows the contracting authority to start the procedure at the same time as sending the documents to the DPPC (expect for accelerated procedures or negotiated procedures without publication of a notice). The decision to start the proceedings (i.e. publication of the notice) in parallel with the controls is a significant one, since the contracting authority cannot be sure that the contract documents do not contain any irregularities. This might lead to a necessity to amend the contract documents, even several times. Therefore the contracting authority is faced between a choice of uncertainty and delays caused by the control process. Nevertheless it is expected that the overall time for purchases can be reduced for those contracting authorities that are brave enough to launch the procedure before the conclusion of the control procedure.

\subsection{Controls integrated in the process}

Once the first part of the procurement process is complete, i.e. the time limit for submitting tenders has been reached; the control process is continued with a control integrated in the process. The DPPC delegates an observer to each procedure who has the right to attend the meetings of the evaluation committee and has to right to observe all documents and decisions related to the procedure. At the end of the procedure all documents have to be sent to the observer who, within 10 working days, issues a closing certificate on the lawfulness of the procedure.

Since 1 January 2017 the contracting authority may award the contract at the same time as the control procedure is carried out and may also conclude the contract; however the contract cannot come into force until the DPPC has issued a supportive closing certificate. In this case the contracting authority is faced with the same dilemma as with ex ante controls. It has to make a decision whether to wait for the closing certificate from the DPPC or award and even conclude the contract in order not to delay the procedure. In the latter case it has to be fairly confident that everything has been carried out lawfully during the procedure. Otherwise it might have to repeat the award process and conclude the contract with a different economic operator. This dilemma also has a significant potential to affect the decisions concerning the exclusion and evaluation of tenders and the award of the contract. Nevertheless, despite causing some uncertainty, the change of the regulation could be beneficial for the contracting authority as it can conclude the contract faster, since it is not necessary to wait for the decision of the DPPC. There are only difficulties if a non-supportive certificate is issued. 


\subsection{Other controls}

In the view of the authors, the most significant control processes that have an effect on the public procurement procedure are those described in sections 3.3 and 3.4 above. Nevertheless it must be highlighted that other control procedures also exist and they too have some potential of impacting the public procurement procedure. For public supply and public service contracts above the EU thresholds and public works contracts above HUF 300 million ex ante control is also carried out for the modification of contracts. Control is first carried out within 5 working days by the Managing Authority on eligibility, accountability and technical aspects, and then the public procurement law aspects of the modification are checked by the DPPC within 13 working days from the receipt of the documents. In all cases the contracting authority has 5 working days for sending the revised documents (if revision is necessary) to the DPPC. Any further comments by the DPPC must be sent to the contracting authority within 7 working days. Once the contract is amended, the amendment also has to be sent to the Managing Authority who may initiate irregularity proceedings or a procedure for remedies if it thinks that the modification is not in conformity with the relevant rules. Therefore extra care must also be taken when the contracting authority decides to modify an existing public procurement contract.

Contracts below the above mentioned thresholds are also subject to control, but that other process is much simpler. In that case the Managing Authority must be notified of the conclusion of the contract amendment and must be provided with the written summary of the procedure and all other procurement documents. The Managing Authority checks these within 7 working days. If any irregularities are found an irregularity procedure, or in case of a breach of the public procurement rules, a procedure for remedies may be initiated.

It must be mentioned that in addition to the above, general controls also exist for all public procurement procedures. Contract notices are controlled by the Public Procurement Authority to see if they conform to formal requirements and public procurement law aspects. However the Authority may only call upon the contracting authority to correct any deemed irregularities, but does not have to power to block the launch of procedures or the coming into force of the contracts. Furthermore the Authority carries out checks on the performance of contracts as well. If irregularities are found, review proceedings may be initiated by the Authority. While these are considered to be less significant and less rigorous than the controls carried out for EU funded procurements, these may also affect the way in which contracting authorities act and the decisions they make during the procedure.

\section{Analysis of Data}

As part of the research, data has been requested from the DPPC on the issuing of the relevant certificates. Besides the types of certificates, the DPPC 
also collected data on the number of cases where the contracting authority issued a non-supportive certificate (i.e. did not allow the procedure to go ahead or continue), but following the revision of documents, a supportive certificate was issued with respect to the same procedure. This latter case means that some decision(s) had to be changed during the procedure, in order to have the possibility to complete it and sign the contract. Furthermore data has been obtained from the Public Procurement Authority on the duration of public procurement procedures from the year 2013 until mid-2017. The changes in the length of procedures can therefore be contrasted with the issuing of certificates and the number of EU funded public procurements.

\subsection{Data selection methodology}

When selecting the data it was important to see quantitative figures on the issuing of certificates to see the volume of the work done by the DPPC and how many public procurement procedures might be affected by its decisions. The split between supportive and non-supportive decisions was also important since it is the latter which has a truly significant effect on the purchases, as in this case the procedure has to be abandoned or re-started. The distinction between the quality control certificates and regularity certificates was also important, since the former has more of a preventive nature in that a procedure containing some irregularity is stopped before it is launched (or before the tenders are evaluated), while the number of regularity certificates indicate the opinion of the DPPC on the whole conduct of the procedure. In the latter case errors are more difficult to be corrected. However in order to see the link between the issuing of certificates and the changing of the behaviour of public authorities, data was requested on the number of cases where there was a change in the process having an effect of regularizing the procedure (i.e. making the public procurement procedure lawful). The number of opinions on contract amendments was also requested in order to see the possible difficulties faced by public authorities after the tendering phase, in case they had to modify the concluded contract for some reason. Finally, to put the issuing of certificated into the wider context, data was used from the Public Procurement Authority on the ratio of EU funded and nationally funded public procurements.

The data selection process was limited, however, by the data that is actually collected and recorded by the DPPC. As regards the time span, data on the issuing of certificates was available from 2012, while data on the changing of certificates was only available for 2015 and 2016. It would have also been useful to obtain figures on the actual length of time it took for the DPPC to issue certificates, however such data could not be provided by the DPPC. Therefore the analysis has to be restricted to any conclusions that could be drawn from the limited amount of data available. 


\subsection{Number of quality control certificates issued}

In the 2012-2016 period the distribution of supportive and non-supportive certificates with respect to the quality control phase (ex ante) were the following:

Figure 1: Number of Quality Control Certificates 2012-2016

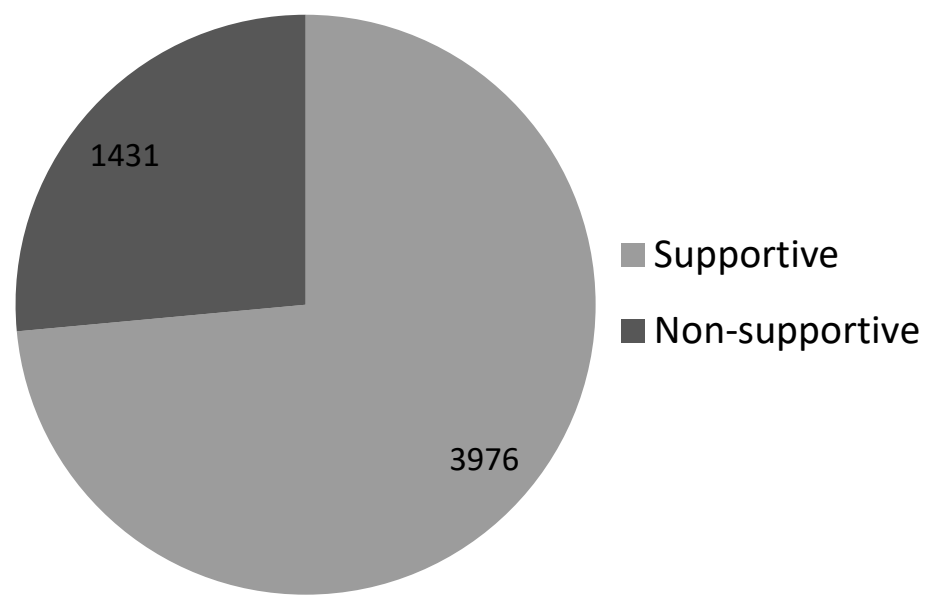

Source: data received from the DPPC.

Table 1: Annual breakdown of Quality Control Certificates sent out

\begin{tabular}{|c|c|c|}
\hline Year & $\begin{array}{c}\text { Type of quality control } \\
\text { certificate }\end{array}$ & Number \\
\hline \multirow{2}{*}{2012} & supportive & 837 \\
\hline & non-supportive & 416 \\
\hline \multirow{2}{*}{2013} & supportive & 1452 \\
\hline & non-supportive & 287 \\
\hline \multirow{2}{*}{2014} & supportive & 768 \\
\hline & non-supportive & 488 \\
\hline \multirow{2}{*}{2015} & supportive & 628 \\
\hline & non-supportive & 166 \\
\hline \multirow{2}{*}{2016} & supportive & 291 \\
\hline & non-supportive & 74 \\
\hline
\end{tabular}

The data shows that when public procurement documents were subjected to ex ante controls (the quality control phase), the majority of contracting authorities received a green light from the DPPC. It was only in 1431 cases within the 4-year period examined where the launch of the procedure was 
denied due to non-compliance with the relevant legislation and principles. In these cases the contracting authority had to change its mind in what to include in the contract documents or in extreme cases decide not to go ahead with the procurement. While there is no data on what change each of these procedures entailed, the errors could relate for example to discriminatory selection criteria, award criteria or technical specifications. These then have to be re-thought by the contracting authority.

Non-supportive certificates amounted to approximately $26 \%$ of all certificates issued. This does not mean that errors were found in such a proportion of cases, since the figure concerning supportive certificates also includes those cases where a non-supportive certificate was later changed to a supportive certificate following an amendment of documents (see below). Therefore the actual rate of errors could in fact be higher. In any case it can be observed from the data that the DPPC has filtered out a significant number of errors in the control process and in many cases the existence of the controls had a direct impact on the conduct of public authorities. In addition it can be supposed that the strict control process also impacted on the conduct of those public authorities that received a supportive certificate. First of all the existence of the control system might have an effect in "regularizing" procedures in the first place. Secondly in many of the procedures the DPPC provides comments on the procurement documents and issues the supportive certificates on the basis of conditions that have to be fulfilled by the contracting authority (e.g. amending or completing certain parts of the documents). Therefore even in many of the 3976 cases when the supportive certificate was issued, decisions had to take into account the opinion (or potential opinion) of the control body.

It must be remembered that prior to 2017, it was unlawful to start the procedure before the supportive quality control certificate was issued, therefore it is possible that contracting authorities relied more on the decision of the DPPC to correct any mistakes and were less careful in their decision on what they included in the procurement documents. It is submitted that in the current regime, described above in section 3, contracting authorities need to take extra care if they decide to launch the procedure before being in possession of a supportive certificates. Otherwise they have to go through the inconvenience of having to modify the procurement documents and possibly even the conditions for participating in the tender, which in certain cases even leads to an obligation to prolong the time limit to submit tenders.

\subsection{Number of regularity certificates issued}

In the 2012-2016 periods the distribution of supportive and non-supportive certificates with respect to the regularity phase (integrated into the process) was the following: 
Figure 2: Number of Regularity Certificates 2012-2016

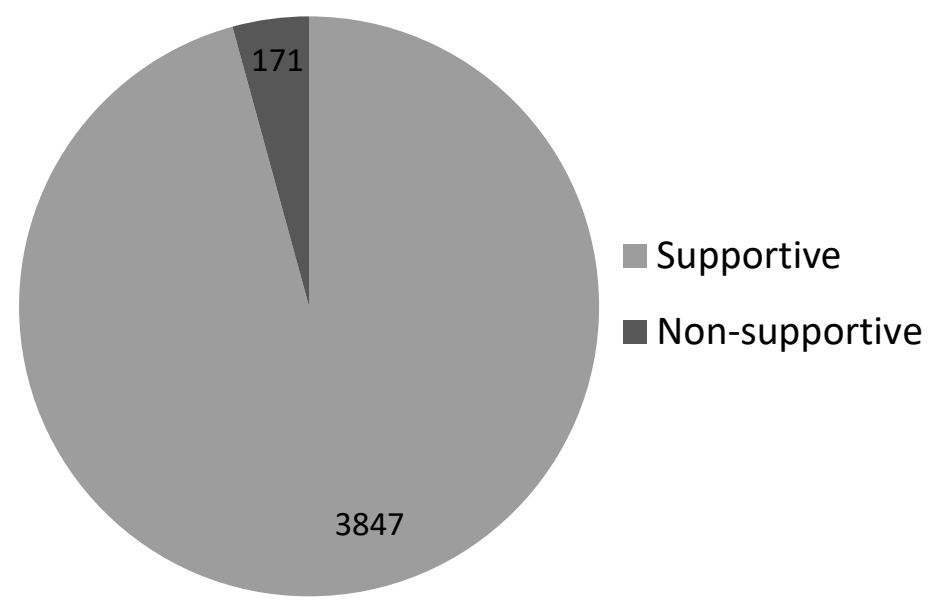

Source: data received from the DPPC.

Table 2: Annual breakdown of Regularity Certificates sent out

\begin{tabular}{|l|l|l|}
\hline Year & Type of regularity certificate & Number \\
\hline $\mathbf{2 0 1 2}$ & $\begin{array}{l}\text { supportive } \\
\text { non-supportive }\end{array}$ & 813 \\
\hline $\mathbf{2 0 1 3}$ & $\begin{array}{l}\text { supportive } \\
\text { non-supportive }\end{array}$ & $\mathbf{2 7}$ \\
\hline $\mathbf{2 0 1 4}$ & supportive & 28 \\
\hline \multirow{2}{*}{$\mathbf{2 0 1 5}$} & non-supportive & 916 \\
\hline \multirow{2}{*}{$\mathbf{2 0 1 6}$} & supportive & 57 \\
\hline & non-supportive & 862 \\
\hline & supportive & 51 \\
\hline & non-supportive & 191 \\
\hline
\end{tabular}

Source: data received from the DPPC.

It can be seen from the data that in the 2012-2016 period compliance with the law during the conduct of the procedure was much higher than during the quality control phase. In the five-year period only 171 non-supportive regularity certificates were issued, which is a relatively low proportion, compared to the total number of certificates, which was 4018 . This means that only just over $4 \%$ of the certificates were non-supportive. Неге again there can be a significant overlap between the two categories as in many cases supportive certificates might have been issued later on for procedures which initially received a non-supportive certificate. However, even if we supposed that in all 171 cases the issuing of the non-supportive certificate was followed by a sup- 
portive certificate, the rate of procedures with a non-supportive certificate first time round would still be only just below $4.5 \%$.

From the above it is evident that the direct impact of the non-supportive certificates has been much less in the regulatory phase, as there were relatively few cases which resulted in a need for the contracting authority to change its decisions. There can be various explanations for this phenomenon. One possible argument is that any irregularities had already been dealt with in the quality control phase and once all the documents were correct, the likelihood of the contracting authority committing errors was reduced. Furthermore, as mentioned in section 3, the DPPC must delegate an observer to each procedure. Normally the observer only controls the documents submitted and only takes part in the actual procedure in exceptional circumstances. Nevertheless the observer has the possibility to comment on the actions of the contracting authority so it is likely that any potential unlawful decisions are settled before the issuing of certificates, so in practice very few non-supportive certificates are issued. Still, it can be said that the control process itself has an actual impact on the way that decisions are made during the procurement procedure.

As discussed in section 3, until the end of 2016, the award of the contract could not be made until the regularity certificate was issued. However, as from 1 January 2017, the contracting authority may decide to award and even conclude the contract, provided that it comes into force only when the supportive certificate by the DPPC is issued. This creates a new dilemma for contracting authorities and it will be interesting to see in the future how this impacts on the decision-making process.

\subsection{Opinions and comments on contract amendments}

The DPPC has also been active in controlling the proposed amendment of contracts. The following table shows the number of such controls and their distribution:

Table 3: Opinions on contract amendments and further comments 2012-2016

\begin{tabular}{|l|l|}
\hline Lawful & 2502 \\
\hline Not lawful & 519 \\
\hline Partially lawful & 304 \\
\hline Total & 3325 \\
\hline
\end{tabular}

Source: data received from the DPPC.

It can be seen from the data that compared to the number of non-supportive regularity certificates; the proportion of contract amendments deemed "not lawful" by the DPPC has been quite high (around 15\%). If we add the "not lawful" and "partially lawful" opinions, then the figure is almost $25 \%$. This is similar to the proportion of non-supportive quality control certificates. This shows 
that while public authorities seem to take extra care during the conduct of the procedure, compared to the preparatory stages, at the stage of contract amendments they again become less aware of the legal requirements. Therefore the direct impact of the control process is also quite significant at this stage of the process.

\subsection{The "regularization" of documents and decisions}

An interesting dimension of the control process involves looking at the number of cases which actually led to contracting authorities taking actions to correct any errors in their documents or the decisions affecting the procedure (i.e. "regularize" documents and decisions). The main purpose of the control process of course is not to punish the contracting authorities for any irregularities, but to help them carry out their procurements in a lawful way, thus avoiding any negative consequences later on both for the contracting authority itself (e.g. having to pay damages) and the Member State (e.g. financial corrections).

The number of cases where errors were corrected, so that a supportive certificate was issued in 2015-2016 was distributed between the types of certificate, as follows:

Figure 3: Amendment of documents in a way to change a non-supportive certificate to a supportive certificate 2015-2016

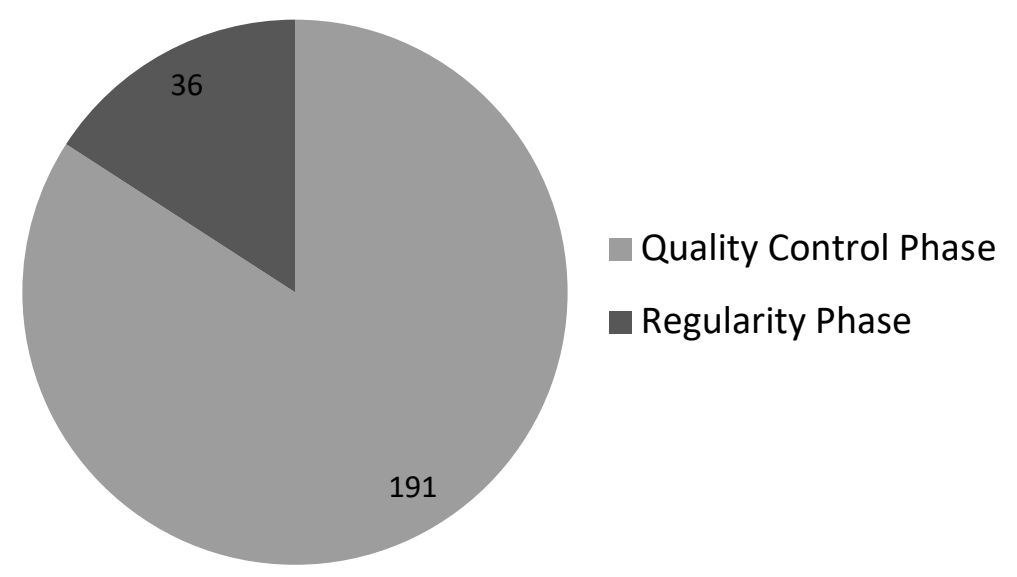

Source: data received from the DPPC.

Table 4: Number of quality control certificates

\begin{tabular}{|l|r|r|}
\hline \multicolumn{1}{|c|}{ Year } & $\mathbf{2 0 1 5}$ & $\mathbf{2 0 1 6}$ \\
\hline Supportive & 628 & 291 \\
\hline Non-supportive & 166 & 74 \\
\hline
\end{tabular}

Source: data received from the DPPC. 
Table 5: Number of regularity control certificates

\begin{tabular}{|l|r|r|}
\hline \multicolumn{1}{|c|}{ Year } & \multicolumn{1}{|c|}{2015} & 2016 \\
\hline Supportive & 862 & 191 \\
\hline Non-supportive & 51 & 8 \\
\hline
\end{tabular}

Source: data received from the DPPC.

In addition there was a change in the DPPC's position from irregular/combined to regular in case of contract amendments in 2015-2016 in a total of 69 cases. ${ }^{5}$ It is unfortunate that no data is available for procedures prior to 2015.

Using the data our findings discussed in sections 4.2 and 4.3 can be confirmed, namely that the control process had much more direct impact on contracting authorities' conduct in the quality control phase than in the regularity phase. There were only 36 occasions in the regularity phase where decisions were "regularized", which is only $16 \%$ of the total number of cases when this happened. The 191 cases of changing to a supportive certificate seem reasonable in the light that in 2015-2016 there were 240 non-supportive certificates. The explanation for the difference is that some contracting authorities might have abandoned their procurement procedures as a result of the non-supportive certificate. Nevertheless it can be seen that in the vast majority of cases errors have been subsequently rectified. The ratio of rectification of errors for the regulatory phase is slightly lower, which shows that controls caused that contracting authorities not to complete the procedure in more cases than in the quality control phase.

The relatively low numbers may also be the result of contracting authorities being more careful about the regularity of their рrocurements and now they have more experience about the DPPC's approach, i.e. the types of errors which lead to issuing a non-supportive certificate. Therefore in 2015-2016 the direct impact of controls were less significant than the possible indirect impact resulting from a "fear" of controls and the possible issuing of nonsupportive certificates.

\subsection{Average duration of public procurement procedures}

It is also interesting to consider the average duration of public procurement procedures as the control system might have impacted on this. Unfortunately the data obtained from the Public Procurement Authority does not separate procedures funded from EU funds and those funded from purely national funds. However the trend in the speed of conducting procedures between 2013 and the first half of 2017 can be seen from the following table:

5 Source: data received from the DPPC 
Table 6: Average duration of public procurement procedures in Hungary ${ }^{6}$

\begin{tabular}{|l|r|}
\hline \multicolumn{1}{|c|}{ Year } & $\begin{array}{c}\text { Average duration } \\
\text { of procedures (days) }\end{array}$ \\
\hline 2013 & 113.15 \\
\hline 2014 & 138.71 \\
\hline 2015 & 156.31 \\
\hline 2016 & 204.85 \\
\hline 2017 (Q1-Q2) & 212.11 \\
\hline
\end{tabular}

Source: Public Procurement Authority.

The table shows that the duration of procedures has increased quite significantly, in fact the average public procurement procedure took almost twice as long in 2017 than in 2013. However if we look at decision speed (the time between the deadline for receiving tenders and the award of the contract), Hungary is still deemed acceptable by the European Commission's 2017 Single Market Scoreboard (2017), as the length of decision-making was below 120 days. In this indicator Hungary did better than the data for the Czech Republic, Ireland, Greece, Italy and Slovakia.

Together with this data the changes in the proportion of EU funded procedures can also be contrasted. It is clear that changes in the proportion of different funding sources in the procurements do not affect the speed at which procurement decisions are made. While for example in 2016 there has been a sharp drop in the percentage of procedures financed from EU funds, the duration of procedures showed a significant increase.

In addition, as shown above, the number of quality control and regularity certificates has also decreased significantly in 2016 in line with the reduction of the number of EU funded procedures. This also suggests that the time taken for public procurement procedures must have also been affected by other factors.

Table 7: Proportion of public procurement procedures connected to EU funds in Hungary

\begin{tabular}{|l|l|l|}
\hline Year & \multicolumn{1}{|c|}{$\begin{array}{c}\text { Value of } \\
\text { procurements }\end{array}$} & \multicolumn{1}{c|}{$\begin{array}{c}\text { Number of } \\
\text { procedures }\end{array}$} \\
\hline 2012 & $54.1 \%$ & $43.2 \%$ \\
\hline 2013 & $61.1 \%$ & $50.8 \%$ \\
\hline 2014 & $49.2 \%$ & $50.2 \%$ \\
\hline 2015 & $38.1 \%$ & $45.9 \%$ \\
\hline 2016 & $29.9 \%$ & $16.2 \%$ \\
\hline
\end{tabular}

Source: Public Procurement Authority.

6 Data includes all procedures with a contract notice both above and below the public procurement thresholds. Data is based on the dates provided by contracting authorities in the relevant notices. 
Unfortunately there is no data available on the actual duration of control procedures carried out by the DPPC. Therefore it cannot be concluded that any of the increase in the duration of the procedures would be due to an increase in the length of the control process. However it can be said that with the process of purchasing taking longer and longer, strict controls lasting several weeks definitely do not help those contracting authorities who wish to carry out EU funded public procurements quickly and effectively. One must remember that the data on the duration only includes potentially the controls integrated in the process, as ex ante controls (at least until 2016) take place prior to the launch of the procedures. This means that the actual process for higher value procedures funded from EU funds is even longer.

\subsection{Discussion of findings and recommendations}

From the above it is clear that the Hungarian control system has a direct effect on some public procurement procedures co-financed by EU funds. Direct influence occurs when the result of the control process leads to an actual change in the public procurement documents, potentially affecting even the final outcome of procedures, i.e. to whom the contract is awarded in the end. It can also be supposed that decisions of contracting authorities are also being influenced indirectly by making them more aware of the correct interpretation of the rules and making them more careful in applying the rules correctly.

It has been found that most influence throughout the procedure occurs in the initial stages of the process, when the procurement documents are submitted to the DPPC. In the controls integrated in the process (regularity phase) much less errors have been found, therefore the direct influence on the decisions of contracting authorities have been much less. This means that the biggest effect on the conduct of public authorities occurs, when they are putting the procurement documents together and setting the subject matter and the conditions of the procurement process.

However the data also shows that in fact the majority of procurements receive a supportive certificate, meaning that no significant errors are found that would preclude permission to go ahead with the procedure. Conditions can of course be set by the DPPC in its decision, but the largest influence occurs when the public procurement is "blocked" by the DPPC and fundamental changes have to be made to the contracting authority's decisions.

It is also interesting to look at how the number of non-supportive certificates compare to the total number of EU funded public procurements in Hungary. The data on the latter category is the following: 
Table 8: Number of public procurement procedures connected to EU funds in Hungary

\begin{tabular}{|l|l|}
\hline 2012 & 3647 \\
\hline 2013 & 6038 \\
\hline 2014 & 7121 \\
\hline 2015 & 6482 \\
\hline 2016 & 1398 \\
\hline
\end{tabular}

If we consider that from 2012 until 2016 there have been 24248 procedures and in the 2012-2016 period in "only" 1431 cases was a non-supportive quality control certificate and in 171 cases a non-supportive regularity certificate issued, then one might conclude that the direct influence of the control procedure only affects an insignificant number of public procurements. However it must be remembered that the DPPC's control only concerns higher value procurements and the data from the Public Procurement Authority includes all public procurements regardless of their value. Therefore it can be concluded that the control of the DPPC is directly affecting a smaller proportion of procurement procedures, but these belong to the higher value categories, therefore has a more significant effect on the correct use of EU funds than would appear from the data.

Despite the seemingly positive impact on the decision-making, one must not forget that the ex ante control system causes the public procurement procedures to be significantly delayed compared to a situation that if no such control existed. It is notable that checking of notices by the Public Procurement Authority (required also for nationally funded procurements), was already thought to delay the launch of the procedures (Tátrai 2011), even though that is a much simpler procedure than the mandatory controls for EU funded procurements. Therefore it is not surprising that contracting authorities in Hungary often complain about the control procedures being too slow and constituting an excessive burden for them when carrying out their public procurements. ${ }^{7}$ The average duration of all public procurement procedures has increased in recent years. Although, as mentioned above, there is insufficient data to prove that this trend has been affected by the control process, a faster and more efficient control system could make the job of contracting authorities somewhat easier. Further, it can be seen that even if all the deadlines set out in the legislation were fully observed by the control body (which might not always be the case) it still adds a significant amount of time for the procedures to be completed where both ex ante control and control integrated in the process are used. In the light of this and the data discussed above, it is questionable whether such a complex procedure is really necessary, especially if errors are found only in a small proportion of procedures. It is also

7 The system applicable as from 1 January 2017 has the aim of lessening the delays caused by the controls, however as discussed above, launching the procedure before controls are finished leads to less legal certainty and possible problems later on in the process. 
questionable whether it is really necessary to check all of the procedures, as this causes a burden and increases the time of the procedures for every single contracting authority engaged in EU funded public procurement.

In light of the number of errors occurring it is evident that putting a strong system of control for EU funded public procurements is inevitable in Hungary. Nevertheless the additional time taken by the existence of the control system is not proportionate to the necessary interference in the decision-making of contracting authorities. Therefore it would be better to have a control system, which takes into account more the necessity of speed and efficiency when conducting public procurements.

In the view of the authors the Government should re-think the necessity of the current system and take steps to streamline the control process. The starting point should be a more in-depth analysis of the behavioural patterns of contracting authorities as a result of the control process. In a policy context, it could be made sure that policy-makers rely on evidence, not assumptions, as suggested by Bavel et al. (2013) in their policy paper written for the European Commission.

Then alternative options should be explored such as controls based on samples in the way that EU projects are audited in general. The relatively small amount of errors found in the control integrated into the process (regularity phase) also questions calls its necessity into question, since it seems that the vast majority of contracting authorities comply with the rules, once the procurement documents are in order. Higher value projects could be subjected to mandatory controls, however it is proposed that the thresholds above which this is done are increased considerably. This would allow the DPPC or any another competent body to focus on the most important cases only where the financial risk is larger.

A concentrating of resources on the most risky procedures or contracting authorities with a poor record of compliance with the rules could also be a viable option. This would also be an incentive for authorities to comply, since then they would not be in the focus of control bodies, resulting in a reduction of administrative burden for them. In parallel the proportion of procedures subject to ex post control could be increased, which does not have an effect of slowing down procedures so much. It is submitted that by switching to a higher proportion of ex post controls the dissuasive effect of the system would not go away, since the possibility of irregularity procedures and the withdrawal of funding would still remain. However contracting authorities could be incentivised to focus more on ensuring the legality of procedures as they would not be able to rely on certificates of the DPPC to ensure prior to or during the procedure that what they are doing is lawful. The DPPC already provides significant guidance for contracting authorities on what aspects should be taken into account when preparing and conducting public procurement, highlighting also the most common errors that are found when preparing procedures (Deputy State Secretariat for Public Procurement Supervision 
2017a and 2017b). Therefore there is already significant help available from the control body that contracting authorities can rely on.

\section{Conclusion}

Hungary has established a very strong control system for public procurements funded from EU-funds. This strict system is used for higher value procurements, while for procedures with a lower estimated value a lighter regime is used. It has been found that ex ante controls carried out by the DPPC has an appreciable impact on the decisions of public authorities when designing their procedures. The controls also seem to have a similar direct impact on the decisions relating to the amendment of contracts. In the phase of conducting the procedure public authorities tend to have a lower error rate as seen from the data on the number of non-supportive certificates, however informal contacts with the DPPC's observer is also liable to influence procedures considerably. Due to insufficient data it cannot be proven that the increasing duration of procedures is caused by delays in the control process, however in the opinion of the authors more efficient controls could be a useful step in improving the situation. Even if the deadlines set out in the legislation had been duly kept by the DPPC the additional time for launching and completing the procedures could be quite significant.

On the positive side, the data shows that in 2015-2016 the majority of errors found by the DPPC have been corrected, so an initial non-supportive certificate was "turned into" a supportive certificate later on. While it can be established that strict controls are necessary in order to avoid the potential loss of EU funds, it is the view of the authors that the actual and potential delays caused by the procedures do not necessarily outweigh the reduction of risks caused by the strong influence contracting authorities' decisions. The revised system, which has been in place since 1 January 2017, is a step in the right direction, but has the problem of the lack of legal certainty. So it is hoped that further revisions will be made to lessen the possible negative impact of controls even further. 


\section{References}

Arrowsmith, S. (ed.) (2011). EU Public Procurement Law: An Introduction. Nottingham. Asia-Link Project.

Bavel, R. et al. (2013). Applying Behavioural Sciences to EU Policy-making. European Commission, Joint Research Centre, Institute for Prospective Technological Studies. EUR 26033 EN.

Bianchi, T. and Guidi, V. (2010). The Comparative Survey on the National Public Procurement Systems across the PPN. Rome.

Department of Contracts (2017). Addressing Fraud and Corruption in Public Procurement. Ministry of Finance of Malta.

Deputy State Secretariat For Public Procurement Supervision (2017a). Minőségellenőrzési útmutató (Guidance on quality control). Prime Minister's Office. Budapest.

Deputy State Secretariat For Public Procurement Supervision (2017b). Szabályossági útmutató (Guidance on regularity). Prime Minister's Office. Budapest.

Dimulescu, V., Pop, R. and Doroftei, I.M. (2013). Risks of corruption and the management of EU funds in Romania. Romanian Journal of Political Science. 13(1), pp. 101-123.

ECA (2011). European Court of Auditors Annual Report concerning the financial year 2011.

ECA (2015). Special Report. Efforts to address problems with public procurement in EU cohesion expenditure should be intensified, European Court of Auditors.

European Commission (2013). Decision of 19.12.2013 on the setting out and approval of the guidelines for determining financial corrections to be made by the Commission to expenditure financed by the Union under shared management, for non-compliance with the rules on public procurement. C(2013) 9527 final.

European Union (2015). PUBLIC PROCUREMENT GUIDANCE FOR PRACTITIONERS on the avoidance of the most common errors in projects funded by the European Structural and Investment Funds.

Fazekas, M. et al. (2013). Are EU funds a corruption risk? The impact of EU funds on grand corruption in Central and Eastern Europe. Working Paper series: CRCB-WP/2013:03, GTI-WP/2013:03. Budapest.

FCCA (2017). Supervision of public procurement. Finnish Competition and Consumer Authority. At <https://www.kkv.fi/en/facts-and-advice/competitionaffairs/supervision-of-public-procurement>, accessed 6 May 2018.

Mazur, J. (2016). A lengyel számvevőszék hozzájárulása a jogalkotáshoz és más legfőbb ellenőrző intézmények tapasztalatai. Pénzügyi Szemle; Budapest. Köt, 61(3), pp. 349-366.

Nyikos, G. and Soós, G. (2016). Kohéziós Politika és közbeszerzés együttes alkalmazásának lehetőségei és kihívásai az új szabályozás fényében. Közbeszerzési Szemle, 6(5), pp. 45-60.

OECD (2013). Monitoring of Public Procurement. Public Procurement Brief 27.

Rendon, R.G. and Rendon, J.M. (2015). Auditability in public procurement: An analysis of internal controls and fraud vulnerability. International Journal of Procurement Management, 8(6), pp. 710-730.

SCA (2016). The Swedish Competition Authority's supervision over public procurement. Adm no. 119/2016. 
Single Market Scoreboard (2017). Performance per Policy Area: Public Procurement. (Reporting period: 01/2016 - 12/2016). European Commission.

Talaga, R and Nyikos, Gy (2014): Cohesion Policy in Transition. Comparative Aspects of the Polish and Hungarian Systems of Implementation, Comparative Law Review (TORUN) 18, pp. 111-139.

Tátrai, T. (2011). A közbeszerzés jogi és hatékonysági aspektusai. Vezetéstudomány, 2010(7-8), pp. 68-76.

Yaremenko, S. and Shatkoviskiy, O. (2018). The Control of Public Procurement Polish Experience Relevant to Ukraine. At <http://eupublicprocurement.org. ua>, accessed 6 May 2018. 